Derechos reservados de El Colegio de Sonora, ISSN 0188-7408

\title{
Flexibilidad del trabajo: discurso y construcción social
}

\author{
Enrique de la Garza Toledo*
}

Resumen: A lo largo de este artículo se presentan diversas teorías y experiencias de flexibilidad laboral en México. El texto $s$ inicia con un resumen de las principales teorías y argumentos discursivos sobre la flexibilización del trabajo en América Latina. Posteriormente se analiza el caso mexicano y sus distintas etapas: 1) de 1980 a 1992, caracterizada por una flexibilización unilateral y el inicio de un nuevo modelo económico; 2) de 1992 a 1994, en que se busca construir una nueva flexibilidad con intervención sindical, pero dirigida por las empresas; y 3) a partir de 1995, se intenta crear una alianza entre empresas y sindicatos mediante la firma de convenios de productividad, sin mucho éxito, y aparecen importantes disidencias en el sindicalismo oficial.

Entre otros aspectos, el trabajo muestra que la ventaja comparativa del bajo salario continúa jugando un papel determinante y constituye uno de los factores que provocan que la modernización de las empresas exporta doras en México no sea muy pronunciada.Asimismo, argumenta que las características de la Ley Federal del Tra bajo, los Contratos Colectivos deTrabajo, las diferentes estrategias empresariales de modernización y las particula ridades de las relaciones industriales y el sistema político

\footnotetext{
* Doctor en sociología, Universidad Autónoma Metropolitana. Se le puede enviar correspondencia a Av. Michoacán y Calzada de la Purísima, Col. Vicentina, C. R. 09340, México, D. F. 09000.Correo electrónico: egt@ xanum.uam.mx
} 
mexicano son elementos que explican las causas de la limitada extensión de la flexibilidad laboral en México.

Abstract. Throughout this article different theories and experiences on labor flexibility in Mexico are presented.The text begins with a summary of the main theories and arguments on labor flexibility in Latin America. Subsequently, the Mexican case and its different stages are analyzed: 1) the period from 1980 to 1992 is a stage which features a unilateral flexibility and the implementation of a new economic model, 2) from 1992 to 1994, a new flexiblity is attempted to create with the participation of unions but still managed by companies, and 3) from 1995 on, an alliance between enterprises and unions has been sought through the signing of productivity agreements, without much success, and significant dissensions in the official labor unionism have appeared.

Among other aspects, this work shows that low wages comparative advantage still plays a determining role and is one of the factors which has caused a lack of modernization in exporting firms in Mexico. In addition, the article argues that characteristics of the Federal Labor Law, collective agreements, different company strategies for modernization, and the peculiarities of industrial relations and the Mexican political system explain the causes for the limited expansion of labor flexibility in Mexico.

\section{La flexibilidad entre la abstracción indeterminada y la realidad concreta}

La flexibilidad del trabajo se ha vuelto palabra clave en los discursos acerca del cambio en las relaciones laborales e industriales en América Latina en los nuevos tiempos. Ha sido impulsada por los gobier- 
nos, apoyados en los conceptos del Banco Mundial acerca de la relación entre competitividad y flexibilidad del mercado de trabajo; las organizaciones empresariales se han mostrado coincidentes con esta necesidad de flexibilización y han respaldado cambios en leyes laborales y en los contratos colectivos en este sentido. En otro nivel, empresas de punta han combinado nuevas formas de organización del trabajo con flexibilidad en la relación laboral de diferentes ma neras. incrementando la proporción de trabajadores eventuales y subcontratados, con la mayor movilidad interna y polivalencia o a través de nuevos esquemas de remuneraciones con presencia creciente de los bonos por productividad y calidad. En el plano académico en América Latina, el surgimiento de las teorías sobre el postfordismo (regulacionismo, de la especialización flexible y neoschumpeterianismo, principalmente) ha llevado la polémica más allá de los neoclásicos en economía (atrincherados en los aparatos de diseño económico estatal y en los organismos internacionales como el Banco Mundial y el FMI). En fin, en América Latina se entrecruzan discursos diversos acerca de la flexibilidad del trabajo, junto a prácticas también diferenciadas.

En el plano del discurso presiona por un lado, desde las cúpulas de diseño económico de los estados, el neoliberalismo, heredero de la gran corriente neoclásica, para el cual es una condición de eficiencia, competitividad y tendencia al equilibrio la flexibilización del mercado laboral. El concepto de trabajo que está detrás es fundamentalmente como un precio; el trabajo es un factor de producción que con los otros se combinan en una función de producción. De esta manera, aunque cuantitativamente el trabajo es variable en cantidad (unidades de trabajo) y en precio, su contenido es estático y reducido a aquellos aspectos fenoménicos. No interesa en esta perspectiva si los mundos de vida de la producción han cambiado el contenido y significado de qué es trabajar, tampoco el carácter de las relaciones sociales que implican trabajar, ni mucho menos los procesos de significación que embeben a estas relaciones, ni como éstas cambian o influyen en el desempeño de la empresa. Tampoco interesa ver al trabajo como campo de fuerzas, como conflicto estructurado, con sus alianzas implícitas o explícitas, sus rupturas, diferencias en significaciones o negociaciones. Para aquella corriente 
no interesan estas mediaciones entre actividad y significación del producir y el precio de la fuerza de trabajo. Finalmente, será el precio el determinante del papel del trabajo en la función de producción. De esta manera se encubren diferencias cualitativas del trabajo detrás del mismo precio y las recomendaciones en términos de política laboral gubernamental o empresarial resultan simplistas: eliminar al máximo las restricciones a la libre asignación del trabajo por el mercado. Es decir, la norma es flexibilizar la oferta y demanda de trabajo, eliminando instituciones y reglamentaciones protectoras que distorsionan aquella libre asignación de este factor, facilitando el empleo y desempleo, el uso de la fuerza de trabajo dentro del proceso del mismo y haciendo fluctuar el salario supuestamente en función de la productividad marginal del trabajo. No insistiremos en las críticas a esta concepción, lo cual hemos hecho en otro momento (De la Garza, 1997), que parten de la idea de actor racional y el creer que la sociedad puede ser autoregulada por el mercado, así como el desconocimiento de que en la producción, la organización y la sociedad en general tienen lugar las luchas por el poder, hay diferencia de intereses y procesos diversos de dar sentido. Es evidente que en ningún pás se ha establecido el modelo neoclásico puro, ni es posible establecerlo; luego este discurso ha servido para justificar la flexibilización abstracta del trabajo, es decir, sin tomar en cuenta su cambio de contenidos ni del contexto. Esto es, el modelo neoclá sico no cumple el papel de ser modelo de sociedad, es demasiado simplista y no incluye niveles importantes que también pueden cambiar; constituye más bien un conjunto de ideas fuerza, de supuestos ideales que son adaptados a condiciones políticas, sindicales y sociales concretas. Pretende convertirse también en sentido común, pero en este nivel, aunque influye, no logra abarcar todo el complejo campo de la cultura; sobre todo no queda claro el enganche en sociedades como las latinoamericanas con sus tradiciones políticas, empresariales, sindicales

El otro discurso es el de la nueva ola del management, es decir, la sistematización occidental de las experiencias japonesas con su respectiva crítica al taylorismo, doctrina que no supone qué es lo que realmente los empresarios hacen en el piso de sus fábricas. Este discurso se mueve más en el nivel micro de la empresa y pone su acen- 
to no en el mercado de trabajo, sino en el proceso productivo y en cómo aumentar su eficiencia. Su contribución en el plano de la ma croeconomía es demasiado general, fuera de aceptar la apertura y de creer que la sumatoria de empresas de creciente productividad y ca lidad se traducirá de al guna manera en prosperidad generalizada. Este discurso que se relaciona con las nuevas formas de organización y el cambio en las relaciones laborales a nivel micro, introduce factores blandos sólo traducibles en forma burda ( burda porque el precio de la fuerza de trabajo no puede discriminar de otros factores) en el salario y el empleo, como la cultura, la identidad con la empresa, el espíritu de grupo, el involucramiento y la participación. La relación entre este discurso y las prácticas en las empresas es compleja. Por un lado, una mayoría de compañías en América Latina están al margen de dicho discurso, que está concentrado sobre todo en la gran empresa. Por otro lado, hay suficientes estudios que muestran la distancia entre discurso empresarial y prácticas de orga nización y relaciones laborales. Predominan ampliamente las anomalías (De la Garza, 1993), aunque los cambios son también reales. Sin embargo, los académicos, buscando salvar la sucesión de paradigmas productivos, han acuñado cinturones de protección a sus teorías: equivalentes funcionales de Freyssenet, hibridación de Abo y la idea de proceso de transición inacabado. El problema que tiene la noción de equivalentes funcionales es que primero no permite descubrir nuevos modelos de producción y que en el límite, como el equivalente es planteado a posteriori, dos modelos completamente diferentes podrían suponerse iguales La hibridación tampoco permite reconocer modelos alternativos $y_{\text {, }}$ en última instancia, al no haber modelos puros, todos serían híbridos. Ver como proceso de transición a la reestructuración productiva es realista, pero el problema es que va acompañado de una suerte de evolucionismo en el que se supone que un modelo privó en el pasado (por ejemplo el fordista) y otro llegará (el postfordista). Estas visiones no dejan de ser muy estructuralistas, el futuro está predeterminado, los actores tendrán que ajustarse a los factores objetivos para ser exitosos y no son importantes las circunstancias particulares.

Han sido principalmente las teorías del postfordismo las que han influido en el mundo académico latinoamericano en problemas co- 
mo la flexibilidad del trabajo. Estas teorías tienen en común procla mar el fin de la producción en masa rígida y el advenimiento por diferentes vías ( producción en masa y especialización flexibles, nuevas formas de organización del trabajo, equipo microelectrónico reprogramable, nuevas formas de regulación que aceptarían la flexibilidad) de un nuevo modo de regulación. Pero, de una manera o de otra, avizoran un mundo laboral flexible, al que habría que dotar de actores con capacidad de negociación tendientes hacia la construcción de nuevas regulaciones flexibles y consensos. Es decir, las teorías del postfordismo en América Latina primero trataron de cumplir el papel de marcos teóricos para interpretar la gran transforma ción, acorde con la tradición intelectual en nuestro continente de tener grandes marcos explicativos ( antes desempeñó este papel la teoría de la dependencia, y en el siglo pasado lo hizo el positivismo de Comte y Spencer). Sin embargo, al descubrirse en la investigación empírica múltiples anomalías, ahora tienen más el papel de norma a seguir en el futuro y en cierta forma ser algo por lo que se lucha, aunque la realidad actual sea algo diferente. Es decir, hacen el papel de utopía, también acorde con otra tradición intelectual en América Latina por la cual el científico social no se concibe como simple testigo que verifica, sino como profeta (de la modernidad, del desarroIlo, del socialismo, de la postmodernidad o del postfordismo). Por ello estas teorías no se falsean estrictamente en América Latina, sino que se constituyen en ideas de futuro, por lo que hay que luchar. Estas grandes concepciones del mundo y del futuro como utopía supuestamente viable, malgré la postmodernidad, han tenido un papel importante en la historia del pensamiento, permiten dar cierta direccionalidad a los conceptos y proposiciones teóricas y pueden ser también grandes guías para la acción. Sin embargo, cabe no confundir el nivel de sus supuestos metateóricos con el diagnóstico propiamente dicho. Cuando los supuestos metateóricos se manejan como proposiciones teóricas, se vuelven inverificables y se cae en la confusión entre diagnóstico y normatividad. En pocas palabras, el papel importante de las teorías del postfordismo en América Latina no evita, primero, problematizar estas doctrinas y, segundo, tratar de ha cer diagnósticos más realistas y con estrategias más de descubrimiento que de justificación. 
Con respecto de la flexibilidad, surgen problemas como los siguientes:

1. Las distinciones que hace S. Wood (1991) entre la japonización como experiencia global japonesa no reproducible en su integridad; los transplantes japoneses; y la doctrina gerencial inspirada en el estilo japonés de management (toyotismo). Vinculado con lo anterior, la importancia o no del sistema de relaciones industriales y no sólo del Human Resource M anagement (HRM), así como de aspectos culturales nacionales en el éxito de ciertas estrategias organizativas.

2. ¿Cuál es la relación entre neoliberalismo y postfordismo en la práctica? En América Latina domina en las políticas económicas el neoliberalismo y a la vez empresas grandes han introducido estilos de management toyotistas.

3. ¿Hay grandes estrategias del management de transformación hacia el toyotismo o se trata de medidas contingentes para la situación concreta?

4. ¿Las combinaciones aparentemente contradictorias en la realidad empírica en América Latina entre nuevas formas de organización con baja calificación, bajo salario, escaso involucramiento son anomalías que se corregirán en el futuro o configuraciones productivas de más larga duración?

5. El concepto flexibilidad del trabajo con sus formas numérica, funcional y salarial es abstracto e indeterminado, y puede aplicarse tanto a la caza del mamut en la prehistoria como a la fábrica más automatizada. Es una simple forma, su contenido dependerá de las relaciones y significaciones, en particular de fuerzas entre aquellos que participan en la producción. Su especificación implica también considerar al sistema de relaciones industriales, el Estado y modelo económico. La forma inversa de proceder es a través de una modelística a priori; el fordismo era rígido, el postfordismo es flexible, y con ciertos atributos, como la redistribución de beneficios, recalificación, ganancia de control sobre el proceso de trabajo por parte de los empleados en el postfordismo, aunque no se presenten en la realidad. Es decir, a la tentación 
modelística se puede oponer el ver a la flexibilidad del trabajo como construcción social. En esta medida su futuro no está predeterminado, se crea dentro de ciertos parámetros que escapan a la voluntad inmediata, pero que definen no una línea de desarroIlo, sino un espacio de posibilidades para la acción. Los límites de dicho espacio son móviles en función de la propia acción. Los empresarios no están obligados por ninguna mano invisible a ser postfordistas: la oIt en su informe sobre El trabajo en el mundo de 1997 habla de dos estrategias a nivel internacional de HRM: la du$\mathrm{ra}$, que se centra en la reducción de costos de producción y que no está reñida con nuevas formas de organización del trabajo, y la blanda, que pone el acento en el factor humano, su estabilidad, recalificación, identidad ( oIT, 1997). Schuman, en su último informe sobre Alemania, reconoce que los nuevos conceptos de producción abarcan solamente al $8 \%$ de los trabajadores de producción y habla de dos modelos de reestructuración: el conservador, que continúa el taylorismo, y el innovativo (Schuman, 1998), muy semejante a lo que habíamos planteado que sucede en la industria en modernización en América Latina (De la Garza, 1997).

6) Un problema particular pero muy relevante es si hay asociación positiva entre productividad y flexibilidad del trabajo, en particular si la presencia de sindicatos inhibe el crecimiento de la productividad.

Tomaremos datos del caso mexicano para ilustrar la problematización de estos temas.

\section{La flexibilidad en México: desarrollo y problematización}

El proceso de flexibilización de las relaciones laborales y en particular, de los contratos colectivos en México ha pasado por tres etapas. La primera, de 1980 a 1992, coincidente con el inicio del nuevo modelo económico y que fue una flexibilización unilateral, es decir, 
los sindicatos fueron excluidos del proceso y vistos como una rigidez que había que minimizar. Este periodo se inició con las primeras plantas automotrices del norte dirigidas al mercado externo con contratos colectivos que contrastaban con los de las antiguas plantas del centro.

Pero fue hasta mediados de los ochenta cuando aparece propia mente en el discurso empresarial el concepto de flexibilización, y contratos de grandes empresas,sobre todo paraestatales,fueron afectados (siderurgia, ferrocarriles, petróleo, automotriz, aviación, etcétera). La forma que adquirió la flexibilización fue la desregulación en favor de la gerencia y la eliminación de prerrogativas a los sindicatos. Es decir, se trataba de una flexibilización unilateral que no siempre fue acompañada de nuevas formas de organización del trabajo, ni mucho menos de una identidad entre empresa y trabajadores. La se gunda etapa se inició en 1992, y fue el intento de construir desde el Estado una flexibilidad con intervención sindical. Aunque dirigida por la empresa, suponía participación del sindicato y cierto nivel de negociación entre estos. Fue el periodo de arranque en forma masiva de la firma de convenios de productividad y de la política de bonos por este concepto que se extendió hasta fines de 1994, año en que estalló la crisis económico-financiera. A partir de 1995, se ha tra tado de reconstruir la alianza entre empresas y sindicatos simboliza da por la firma de convenios de productividad, sin mucho éxito ni convicción; en cambio, han aparecido disidencias importantes con respecto al sindicalismo oficial como novedad más importante de este periodo.

El análisis del contenido y extensión de la flexibilidad no se pue de desentender en México de la política estatal (el corporativismo de Estado sigue siendo dominante) del comportamiento y políticas ma croeconómicas (el privilegio de búsqueda de equilibrios y control de la inflación sobre el crecimiento y distribución del ingreso), de las políticas sindicales ( la subordinación de los sindicatos al Estado) y de las estrategias empresariales de modernización (la presencia de varias estrategias en el sector modernizado, una de las cuales privilegia la reducción de costos de producción). 
La primera etapa de la flexibilización: resultados

A inicios de los noventa, el término flexibilidad era moneda corriente en los discursos empresariales, estatales y sindicales en Mé xico. Veremos en qué medida se extendió, así como las formas y contenidos que adquirió.

La flexibilidad del trabajo en el ámbito de la empresa puede analizarse con respecto a dos dimensiones la organización del trabajo y las relaciones laborales. En cuanto a la organización del trabajo, la encuesta ENESTYC de 1991 ( 5000 establecimientos manufactureros a nivel nacional, con muestra representativa por rama y tamaño de es tablecimiento) y la encuesta mim de 1994 (muestra de 500 establecimientos manufactureros distribuida en 14 zonas del país y realizada por la Maestría en Sociología del Trabajo de la UAM-I) proporcionan indicadores de extensión de las nuevas formas de organización del trabajo. Primero, en los establecimientos grandes $\boldsymbol{s e}$ concentraban las innovaciones organizacionales, aunque en este estrato solamente el $\mathbf{1 2 . 8 \%}$ de los establecimientos aplicaban el justo a tiempo (JIT) y el $18 \%$ el control estadístico del proceso, dos de las técnicas vinculadas con la organización más importantes actualmente.

En lo que se refiere a cambios básicos en la organización, en e cuadro 1 se puede ver que la reducción de categorías laborales o bien el nivel bajo de dichas categorías, que puede ser indicador de aplica ción de multihabilidades en los trabajadores, sólo aparecía en el $6.7 \%$ de los establecimientos grandes; en los otros dos estratos este porcentaje era mayor, pero es posible que se deba a la extensión entre pequeños y medianos de formas arbitrarias de organización. De la misma manera, en los establecimientos grandes el porcentaje en al que se fusionaban tareas de producción con control de calidad era del $25.7 \%$, producción con mantenimiento $4.4 \%$, y cuando el trabajador es supervisado por el propio grupo o equipo de trabajo solamente en el $5.9 \%$.

Indicadores adicionales de organización pueden verse en el cua dro 2. Son los establecimientos grandes los que sobre todo hacían estudios de tiempos y movimientos, y tenían y aplicaban manuales de puestos, posibles indicadores de una forma de organización taylorista del trabajo. Como complemento de la visión anterior de la 


\section{Cuadro 1}

\section{Características de la organización del trabajo en manufactura (porcentaje de establecimientos en cada estrato)}

\begin{tabular}{|l|c|c|c|c|}
\hline & $\begin{array}{c}\text { Nivel bajo de } \\
\text { categorías laborales }\end{array}$ & $\begin{array}{c}\text { Fusión producción } \\
\text { control de calidad }\end{array}$ & $\begin{array}{c}\text { Fusión producción } \\
\text { y mantenimiento }\end{array}$ & $\begin{array}{c}\text { Supervisión } \\
\text { por el grupo }\end{array}$ \\
\hline Grande & 6.7 & 25.7 & 4.4 & 5.9 \\
Mediano & 41.5 & 31.0 & 6.9 & 4.6 \\
Pequeño & 23.5 & 48.8 & 26.4 & 6.1 \\
\hline
\end{tabular}

Fuente: Maestría en Sociología del Trabajo (1994) Mıм.

\section{Cuadro 2}

\section{Aspectos adicionales de la organización del trabajo} en manufactura (porcentaje de establecimientos en cada estrato)

\begin{tabular}{|l|c|c|c|c|}
\hline & $\begin{array}{c}\text { Hay manuales } \\
\text { de puestos y los usan }\end{array}$ & $\begin{array}{c}\text { Hay estudios de tiempos } \\
\text { y movimientos }\end{array}$ & $\begin{array}{c}\text { Movilidad } \\
\text { interna alta }\end{array}$ & $\begin{array}{c}\text { Nivel alto de } \\
\text { involucramiento }\end{array}$ \\
\hline Grande & 86.2 & 78.4 & 1.5 & 4.6 \\
Mediano & 71.1 & 72.6 & 1.2 & 4.7 \\
Pequeño & 39.8 & 44.0 & 0.4 & 6.0 \\
\hline
\end{tabular}

Fuente: Maestría en Sociología del Trabajo (1994) MIM.

organización, en los establecimientos grandes la movilidad interna de nivel alto resultó muy restringida ( $1.5 \%$ de los establecimientos grandes), así como también el nivel alto de involucramiento de los trabajadores ( $4.6 \%$ de los grandes).

Es decir, en cuanto a nuevas formas de organización del trabajo es probable que éstas se concentrasen en los establecimientos grandes,pero su extensión en forma sistémica estaba poco extendida; se 
trataba más bien de aspectos parciales de la calidad total y el justo a tiempo, aplicados en un segmento minoritario de gran empresa. La ENESTYC reportaba que las empresas grandes habían hecho cambios organizativos hacia 1991, dependiendo de su amplitud, andaban entre $1.5 \%$ y $21.4 \%$ de los establecimientos de este tamaño.

Los resultados nacionales de la encuesta mim pueden verse en el cuadro 3. Solamente en las empresas con productividad alta se encontró que la flexibilidad era alta. En cambio, la flexibilidad fue baja en la mayoría de los establecimientos exportadores y no exportadores, otro tanto sucedió entre capital nacional o extranjero, sus niveles de flexibilidad fueron bajos y muy semejantes entre ś; en cambio, las pequeñas empresas y medianas tendieron a ser más rígidas que

\section{Cuadro 3}

Flexibilidad laboral (porcentaje de establecimientos)

14 zonas industriales - nivel de flexibilidad

\begin{tabular}{|c|c|c|c|}
\hline Establecimientos & Baja & Media & Alta \\
\hline $\begin{array}{r}\text { Exportador } \\
\text { Sí } \\
\text { No }\end{array}$ & $\begin{array}{l}77.9 \\
71.7\end{array}$ & $\begin{array}{l}22.1 \\
28.3\end{array}$ & $\dot{-}$ \\
\hline $\begin{array}{ll}\text { Capital } & \\
& \text { Extranjero } \\
\text { Nacional }\end{array}$ & $\begin{array}{l}71.7 \\
74.6\end{array}$ & $\begin{array}{l}28.3 \\
25.4\end{array}$ & - \\
\hline $\begin{array}{l}\text { Tamaño } \\
\begin{array}{l}\text { Pequeña } \\
\text { Mediana } \\
\text { Grande }\end{array}\end{array}$ & $\begin{array}{l}86.1 \\
79.3 \\
50.5\end{array}$ & $\begin{array}{l}13.9 \\
20.7 \\
49.5\end{array}$ & $\begin{array}{l}- \\
-\end{array}$ \\
\hline $\begin{array}{l}\text { Productividad } \\
\text { Baja } \\
\text { Media } \\
\text { Alta }\end{array}$ & $\begin{array}{r}75.4 \\
100.0 \\
55.0\end{array}$ & $\begin{array}{r}25.6 \\
. \\
-\end{array}$ & $\begin{array}{l}- \\
-\end{array}$ \\
\hline
\end{tabular}

Fuente: De la Garza (1998). 


\section{Cuadro 4}

Nivel de flexibilidad laboral más frecuente por zona y tamaño de establecimiento

\begin{tabular}{|c|c|c|c|c|}
\hline $\begin{array}{l}\text { Tamaño de } \\
\text { establecimiento }\end{array}$ & Tijuana & Aguascalientes & $\begin{array}{l}\text { Orizaba } \\
\text { Veracruz }\end{array}$ & Yucatán \\
\hline $\begin{array}{l}\text { Pequeña } \\
\text { Mediana } \\
\text { Grande }\end{array}$ & $\begin{array}{l}\text { Baja } \\
\text { Baja } \\
\text { Baja }\end{array}$ & $\begin{array}{l}\text { Baja } \\
\text { Baja } \\
\text { Baja }\end{array}$ & $\begin{array}{l}\text { Baja } \\
\text { Baja } \\
\text { Baja }\end{array}$ & $\begin{array}{l}\text { Baja } \\
\text { Baja } \\
\text { Baja }\end{array}$ \\
\hline
\end{tabular}

Fuente: Ibid., encuesta MIm

Nota: Son los niveles más frecuentes en cada estrato.

las grandes, sin que en estas últimas se alcanzaran niveles altos de flexibilidad.

Por zonas del país, se observa en el cuadro 4 que por tamaños de establecimiento los niveles de flexibilidad en todas las zonas ana lizadas fue bajo, lo mismo en las medianas; en cambio, entre las

\section{Cuadro 5}

Porcentaje de trabajadores de planta, de tiempo parcial, por hora y subcontratados según tamaño de establecimiento

\begin{tabular}{|l|r|c|c|c|}
\hline & Planta & Tiempo parcial & Por hora & Subcontratados \\
\hline Total & 85.6 & 0.5 & 0.1 & 1.9 \\
Grande & 86.5 & 0.16 & 0.03 & 1.8 \\
Mediana & 86.2 & 0.3 & 0.06 & 1.6 \\
Pequeña & 89.05 & 0.8 & 0.4 & 1.7 \\
Micro & 77.1 & 1.3 & 0.07 & 2.7 \\
\hline
\end{tabular}

Fuente: ENESTYC, STYPS-OIT, 1992. 
empresas grandes las zonas en las que la flexibilidad era de nivel medio fueron Mexicali, Hermosillo, Saltillo, Guadalajara, Puebla y Orizaba ( no todas incluidas en el cuadro).

Indicadores complementarios de la extensión de la flexibilidad del trabajo se pueden obtener de la ENESTYC. En el cuadro 5, se aprecia que en todos los tamaños de establecimientos predominaron los trabajadores de base, que el uso del tiempo parcial, el trabajo por hora y los trabajadores subcontratados fue muy limitado. Esto nos habla de una flexibilidad numérica baja, coincidente en términos generales con los resultados de la encuesta MIM, tomando en cuenta que los indicadores de esta última son más sofisticados que los de la ENESTYC. En cuanto a la movilidad interna entre categorías o puestos, se deduce del cuadro 6 que no era alta, como tampoco el número promedio de horas extras a la semana trabajadas por los obreros; en estos dos indicadores hay diferencias importantes por tamaño de es tablecimiento.

\section{Cuadro 6}

Movilidad interna y horas extras por tamaño de establecimiento

\begin{tabular}{|l|c|c|}
\hline & Movilidad interna* & $\begin{array}{c}\text { Horas extras en el mes } \\
\text { (Obreros hombres) }\end{array}$ \\
\hline Total & 17.0 & 10 \\
Grande & 19.9 & 10 \\
Mediana & 17.7 & 12 \\
Pequeña & 18.1 & 9 \\
Micro & 12.4 & 7 \\
\hline
\end{tabular}

* Tasa de rotación del personal entre distintos puestos

Fuente: ENESTYC, STYPS-OIT, 1992. 


\section{Cuadro 7}

Porcentaje de los bonos por productividad, calidad, asistencia y puntualidad en el total de remuneraciones pagadas al personal ocupado por tamaño de establecimiento

\begin{tabular}{|l|l|}
\hline Total & $2 \%$ \\
\hline Grande & 1.9 \\
Mediano & 2.4 \\
Pequeño & 3.4 \\
Micro & 0.6 \\
\hline
\end{tabular}

Fuente: ENESTYC, STYPS-OIT, 1992.

Finalmente, en cuanto a la flexibilidad salarial, se observa en el cuadro 7 que la importancia de los bonos por productividad, calidad, asistencia y puntualidad en el total de las remuneraciones pa gadas al personal ocupado en la industria manufacturera fue muy baja en el total de la industria, en cualquiera de los estratos de ta maño de establecimiento.

\section{Cuadro 8}

Niveles altos de bilateralidad formal, informal y total en la industria manufacturera (porcentaje de establecimientos)

\begin{tabular}{|l|c|c|c|}
\hline & \multicolumn{2}{|c|}{ Bilateralidad sindical } & Bilateralidad total \\
\hline & Formal & informal & \\
\hline Grande & 8.3 & 5.3 & 14.3 \\
Mediana & 5.6 & 1.4 & 0.0 \\
Pequeña & 0.6 & 1.5 & 0.0 \\
\hline
\end{tabular}

Fuente: MIM. 


\section{Cuadro 9}

Porcentaje del valor de la producción

generada por subcontratistas en la industria manufacturera

\begin{tabular}{|l|c|}
\hline Tamaño & Porcentaje \\
\hline Total & 4.2 \\
Grande & 3.3 \\
Mediano & 4.3 \\
Pequeño & 4.0 \\
Micro & 5.9 \\
\hline
\end{tabular}

Fuente: ENESTYC (1995), sTyPS.

\section{Cuadro 10}

Porcentaje de materias primas importadas en la industria manufacturera

\begin{tabular}{|l|l|l|l|}
\hline Tamaño & 1989 & 1991 & 1994 \\
\hline Total & 27.3 & 31.6 & 41.8 \\
Grande & 32.7 & 35.0 & 43.7 \\
Mediana & 23.0 & 25.5 & 38.3 \\
Pequeña & 11.8 & 16.2 & 38.0 \\
Micro & 18.6 & 40.9 & 37.3 \\
\hline
\end{tabular}

Fuente: ENESTYC $(1992,1995)$, тTYPS. 


\section{Cuadro 11}

Porcentaje de establecimientos manufactureros que realizaron actividades conjuntas ( comercialización, financiamiento, capacitación, ventas y diseño) en 1994

\begin{tabular}{|l|r|}
\hline Tamaño & Porcentaje \\
\hline Total & 3.2 \\
Grande & 12.6 \\
Mediano & 8.1 \\
Pequeño & 6.5 \\
Micro & 2.8 \\
\hline
\end{tabular}

Fuente: ENESTYC (1995), sTyPS.

\section{Cuadro 12}

Porcentaje de los ingresos de los establecimientos manufactureros dedicados a investigación y desarrollo tecnológico

\begin{tabular}{|l|c|c|}
\hline Tamaño & 1991 & 1994 \\
\hline Total & 0.6 & 1.0 \\
Grande & 0.7 & 1.1 \\
Mediano & 0.9 & 1.2 \\
Pequeño & 0.5 & 0.6 \\
Micro & 0.3 & 0.3 \\
\hline
\end{tabular}

Fuente: ENESTYC (1992, 1995), sTyPS. 
La etapa de la concertación: los convenios de productividad

Para ver en qué medida la resistencia de los sindicatos puede en México contribuir a la construcción de la flexibilidad del trabajo es conveniente analizar, además de los contenidos de los contratos colectivos de trabajo, el nivel de bilateralidad formal,informal y total como aparece en $\mathrm{e}$ cuadro 12. Entendemos por bilateralidad sindical la toma de decisiones conjuntas con la empresa. Como se ve en el cuadro anterior, el nivel alto de bilateralidad corresponde a porcentajes muy bajos de establecimientos en todos los estratos considerados, tanto en sus aspectos formal, informal como tota.

En 1992, se pensó desde el Estado que la mejor manera de proseguir con la modernización de las empresas era hacer partícipes a los sindicatos. En este tenor, se firmó el Acuerdo Nacional para la Elevación de la Productividad y la Calidad. En este documento se detalla la propuesta gubernamental de un pacto productivo que hace suyos los conceptos más actuales de la calidad total y establece un marco de bilateralidad entre empresas y sindicatos;además, enuncia todo un modelo de industrialización. Analizaremos a continuación cuál es la suerte que han corrido los convenios de productividad des prendidos de este acuerdo.

El análisis de las empresas que han establecido acuerdos de productividad permite diferenciarlos, dependiendo de cuál es la estrategia empresarial de reestructuración, por cambio tecnológico, organizacional o en las relaciones laborales. Cuando la política de personal no se concibe como factor central para elevar la productividad, es probable que las gerencias muestren poco interés hacia los pactos bilaterales. Incluso cuando se considera relevante la política de personal, las gerencias pueden optar por pactos de escasa bilateralidad.

Podríamos clasificar los pactos de productividad en dos tipos. activos y pasivos. En los primeros, el sindicato se constituye interlocutor activo en los planes de productividad, y despliega una amplia participación en su diseño, ejecución y evaluación. En función del programa de productividad, el sindicato puede intervenir en la toma de decisiones que involucran aspectos tecnológicos, organizacionales, de capacitación, de condiciones y medio ambiente de trabajo, de medición de la productividad, y en la determinación de los criterios para distribuir los beneficios económicos. 
Los pactos de productividad pasivos limitan la acción sindical a la mera aceptación de los proyectos empresariales a cambio de la preservación de ciertas condiciones de trabajo y, en especial, de la definición de incentivos por productividad. En este caso, el sindicato no participa en el diseño de los planes correspondientes ni en la determinación de los indicadores de productividad. Se trata, pues, de un pacto instrumental que no modifica las relaciones laborales entre empresa y sindicato. En pocas palabras, sanciona el "dejar hacer" empresarial a cambio de algunos ingresos suplementarios para los tra bajadores.

\section{Los pactos activos}

A la fecha son pocos los pactos activos, y no tenemos bases para sostener que proliferarán en el futuro inmediato. Entre los pactos de este tipo se encuentran los deTeléfonos de México (TELMEX) y la compañía de Luz y Fuerza del Centro (CLFC).

El caso de telmex es con mucho el más desarrollado. La inclusión de la cláusula 194 en el contrato colectivo de 1990 permitió que el sindicato participara en los programas de productividad. Posteriormente, empresa y sindicato firmaron el "Convenio sobre productividad, calidad y capacitación para la modernización integral de TELMEX" (29 de noviembre de 1990), mediante el cual se estableció:

- el derecho de los trabajadores para participar propositiva y crea tivamente en la modernización de la empresa, así como el derecho a recompensas por esfuerzos adicionales;

- el compromiso para que empresa y sindicato diseñen un progra ma para la elevación y el mejoramiento de la productividad y la calidad;

- la definición bilateral de los procesos de modernización administrativa y operativa;

- la promoción de una nueva cultura laboral basada en la concertaxión y los beneficios mutuos;

- la ratificación del modelo de calidad que había sido firmado por iniciativa del sindicato en 1989;

- la implantación de programas de capacitación con el objetivo de estimular la capacitación creativa; 
- la promoción del trabajo en equipo y el mejoramiento de las condiciones de vida en el trabajo;

- la constitución de una comisión mixta encargada de definir los criterios e indicadores para medir la productividad;

- el compromiso de la empresa para capacitar a los directivos en calidad tota.

El sentido general de los acuerdos sobre productividad de los telefonistas, la especificación paulatina de los mismos y el grado de avance en su ejecución permiten afirmar que este es el caso más desarrollado en el contexto mexicano. Por ello, no pocas veces sirve de modelo a otros sindicatos al momento de establecer sus propios convenios de productividad.

El caso del convenio entre el Sindicato Mexicano de Electricistas (SME) y la CLFC, aunque es un poco diferente, representa también una posición activa del sindicato con respecto a la industria eléctrica que estipuló el compromiso estatal para crear una nueva empresa a partir de la CLFC. Para ello, se formaron las comisiones mixtas de productividad y de estructura administrativa y bases financieras. LoS trabajos de la primera comisión concluyeron con una definición amplia de la productividad en un sentido semejante al que aparece en el contrato de TELMEX y que posteriormente estaría en el ANEPC. Dicho concepto abarcó las condiciones de trabajo, el elemento salarial y la capacitación de la fuerza de trabajo. Más aún, el Sindicato Mexicano de Electricistas (SME) logró también que se incluyeran en la definición de productividad algunos elementos relacionados con la gestión gerencial que desbordan el ámbito de los procesos de trabajo, tales como el estilo de dirección, la calidad y disponibilidad de recursos materiales, la comunicación horizontal y vertical, la asigna ción de recursos financieros, la innovación tecnológica, los progra mas de desarrollo cultural y social para los trabajadores y la comercialización de los productos. Además, como parte de su estrategia,el SME optó por la aplicación de indicadores globales de productividad para no fomentar la fragmentación de los intereses de los agremiados. 


\section{Los convenios defensivos}

En abril de 1992, el Sindicato Único deTrabajadores Electricistas de la República Mexicana (sUTERM) firmó su primer convenio de productividad con la Comisión Federal de Electricistas (CFE). Este convenio establece que la iniciativa de los planes de productividad, su medición y evaluación son facultades exclusivas de la empresa.Adicionalmente, reglamenta los horarios para impartir el adiestramiento y la capacitación, y añade que habrá un estímulo para los traba jadores que asistan a los cursos, pero deja en manos de la empresa la decisión sobre los contenidos de la capacitación. La concepción de productividad que sustentó el diseño de este convenio se manifiesta con toda claridad en estipulaciones como las siguientes: para aumentar su productividad los trabajadores pueden optar por la reducción de su periodo vacacional a cambio del correspondiente pago extra; en el renglón de permisos, se añade el término "sin goce de salario"; se crea el incentivo catorcenal, que consiste de un día de salario tabulado sin considerar prestaciones, para la asignación del incentivo solamente se toma en cuenta la asistencia y la puntualidad. Como consecuencia de la inconformidad de los trabajadores, $s$ firmó posteriormente un segundo convenio de productividad más complejo y de mayores alcances.

Al inicio de 1994, la Asociación Metropolitana de Ejecutivos de Relaciones Industriales realizó una encuesta de convenios de productividad, cuyos resultados más importantes fueron los siguientes:

- la mayoría de la empresas celebraron sus convenios de productividad hasta 1994, es decir presionadas por el Pacto de Octubre de 1993.

- predomina el pago individual de bonos.

- el $58 \%$ de las empresas que firmaron contratos colectivos al inicio de 1994 y establecieron convenios fijaron un dos por ciento del salario base por concepto de bonos, igual a lo que el Pacto estableció para los salarios mínimos.

Es decir, la firma de convenios por productividad $s$ ha extendido espectacularmente a partir de enero de 1994 y el pacto firmado 
en octubre de este año volvió a considerar un incremento al salario base de acuerdo con la inflación esperada en 1995 (4\%) más otro por incremento en la productividad en 1994 (2\%).

La Secretaría del Trabajo hizo un censo de convenios de productividad en 1994, cuyos resultados pueden resumirse de la siguiente manera:

- los convenios de productividad están muy concentrados en las empresas grandes, pues el $\mathbf{8 7 . 8 \%}$ de ellos correspondían a empresas de más de 300 trabajadores.

- sólo el $50 \%$ de los convenios prevén medir, diagnosticar y estimular económicamente la elevación de la productividad.

- en 1994 el $79.4 \%$ de los convenios otorgaron $2 \%$ o menos por bono y estos convenios abarcaban al $\mathbf{8 7 . 2 \%}$ de los trabajadores con este tipo de acuerdo.

- la mayoría de los convenios sólo consideran el desempeño general de la empresa y no miden el individual, grupal o departamental.

- las metas más comunes se reducen a la asistencia y la puntualidad.

En todos los casos, los convenios declaran en términos semejantes el compromiso de las partes para enfrentar los desafíos de la globalización, promover una nueva cultura laboral e involucrar al sindicato y los trabajadores en la modernización productiva;asimismo, reconocen la necesidad de nuevos contenidos en la capacitación y de transitar del enfrentamiento y la desconfianza entre capital y trabajo hacia un clima de concertación y colaboración. Pero en lo correspondiente a sus diferencias, encontramos convenios que promueven bonos individuales, grupales o mixtos. Unos contemplan el funcionamiento de comisiones mixtas mientras que otros no mencionan nada al respecto, 0 asignan sus eventuales funciones a las instancias sindicales tradicionales. Algunos convenios que incluyen comisiones mixtas les asignan funciones amplias, cercanas a lo que hemos denominado estrategia activa. Por otra parte, la determinación de los parámetros de medición y las formas de pago se establecen tanto unilateral como bilateralmente. Unos fijan un máximo en el monto 
de los bonos con respecto al salario base, mientras que otros no indican límite alguno. También varían las condiciones para recibir los bonos: en unos casos basta con alcanzar ciertas metas preestablecidas; en otros, se deja abierto el porcentaje que se puede recibir cuando se superan valores históricos de ciertos parámetros de productividad. Los recursos totales destinados a los bonos pueden definirse con anterioridad e indicando un tope máximo o pueden depender, sin límite alguno, de los resultados obtenidos Por último, cabe mencionar que en algunos casos las empresas ofrecieron los bonos por productividad a cambio de la flexibilización del contrato colectivo, la polivalencia o la compactación del tabulador.

\section{Avance y limitaciones de la flexibilización}

Hacia el año de 1994, la Secretaría del Trabajo y Previsión Social (sTyPS) realizó su segunda encuesta ENESTIC con una muestra representativa de alrededor de 5000 establecimientos manufactureros. A partir de dicha encuesta y de la de 1991, es posible captar el avance en flexibilidad en la industria mexicana

Entre 1991 y 1994 no hay un cambio apreciable en el uso de subcontratistas; el porcentaje del valor de la producción generada por estos es muy bajo: $4.2 \%$ en la manufactura y $3.3 \%$ en los establecimientos grandes Hay dos explicaciones al respecto. Una es el aumento espectacular de laimportación de insumos a raíz de la apertura comercial que ha desarticulado cadenas productivas o impedido la creación de nuevas. La otra explicación es laboral: los salarios en el sector moderno de la economía, incluyendo el exportador, son tan bajos que la delegación en subcontratistas no presenta ventajas partculares, añadiendo que se trata de los mismos sindicatos que controlan a los trabajadores tanto en subcontratadas como subcontratantes.

Lo anterior es probable que contribuya al mantenimiento de un círculo pernicioso para el desarrollo industrial. Las empresas grandes que son sobre todo exportadoras importan de manera creciente sus insumos y no emplean subcontratistas internos. Debido a ello, la pequeña y mediana empresa no se ve impulsada a modernizarse, cambiar de tecnología, organización, funcionar justo a tiempo o con niveles aceptables de calidad. Este círculo pernicioso se cierra tam- 
bién por la escasa difusión de los distritos industriales y clusters. El porcentaje de establecimientos que en 1994 realizaron actividades conjuntas de investigación,comercialización,capacitación, financia miento o ventas es pequeño.

Un ejemplo claro de este comportamiento que desarticula cadenas productivas y de clientes y proveedores es la maquila del norte, que, a pesar del discurso sobre clusters, adoptado ahora por el gobierno mexicano según recomendaciones del Banco Mundial, mantiene sus insumos nacionales en alrededor de $2 \%$ del total desde el inicio del actual modelo económico en 1980.

Tampoco ha cambiado mucho la actitud de las empresas con respecto a investigación y desarrollo; sus gastos en estos rubros se han mantenido en niveles irrisorios. Sorprenden también las cifras tan bajas dedicadas al pago de trasferencia de tecnología, que puede ser indicador de un uso ilegal y hechizo de ésta en la mayoría de lasempresas. En cuanto a la maquinaria y equipo empleados, saltan a la vis ta las grandes diferencias en el uso de instrumentos para el control de calidad entre los establecimientos grandes y pequeños y micro; ien los primeros la mayoría los utiliza, en los últimos una pequeña minoría.Asimismo, el porcentaje en el valor de la maquinaria y equipo de los tornos de control numérico y de los robots es muy pequeño en todos los tamaños de establecimiento, aunque superior en los grandes.

En cambio, la extensión de las nuevas formas de organización del trabajo parece que se ha incrementado a partir de 1994.

Sin embargo, la introducción de nuevas formas de organización no lleva aparejada el mismo nivel de flexibilidad numérica, ni directa ni a través de subcontratistas. En las empresas predomina el traba jador de planta con contrato por tiempo indeterminado, y el trabajo a tiempo parcial y por horas es despreciable. La explicación puede tener dos vertientes una es el tradicional monopolio que los sindica tos oficiales han tenido sobre $e l$ mercado de trabajo y la demanda histórica atendida por estos de obtención de definitividad, pero tal vez la más importante sea por el lado de los empresarios, primero por los efectos negativos que sobre la productividad puede tener la inestabilidad laboral y, segundo, aś como en la explicación para el no uso de subcontratistas, porque los trabajadores de base tampoco 
cuestan tanto como para pensar en substituirlos por eventuales 0 subcontratistas.

En cuanto a la flexibilidad en el salario a través de bonos, se ve que donde éstos $s$ han extendido es en empresas grandes, no así en las pequeñas y medianas. Sin embargo, el monto de los bonos es pequeño en las grandes y más alto en las micro, posiblemente porque la encuesta no distinguió entre esquemas nuevos de remuneraciones de aquellos relacionados con el pago a destajo tradicionales. De cualquier forma, los costos salariales han disminuido drásticamente entre 1991 y 1994 con respecto de los costos totales, lo cual se refleja en la decadencia de los salarios reales en la manufactura y el personal ocupado, no tanto por la innovación tecnológica, sino por una mayor racionalización con intensidad en el trabajo.

Las empresas y sindicatos que depositan sus contratos colectivos en la Junta Federal de Conciliación y Arbitraje corresponden a las compañías que tienen establecimientos en más de una entidad fede-

\section{Cuadro 13}

Porcentaje de los ingresos de los establecimientos manufactureros dedicados a la compra o pago por transferencia de tecnología

\begin{tabular}{|l|c|c|}
\hline & \multicolumn{2}{c|}{ Porcentaje } \\
\hline Tamaño & 1991 & 1994 \\
\hline Total & 3.1 & 2.1 \\
Grande & 3.0 & 2.0 \\
Mediano & 3.9 & 2.0 \\
Pequeño & 2.4 & 1.8 \\
Micro & 3.8 & 3.4 \\
\hline
\end{tabular}

Fuente: ENESTYC (1992,1995), sTyPS. 


\section{Cuadro 14}

Porcentaje de los ingresos de los establecimientos manufactureros que utilizan instrumentos para el control de calidad

\begin{tabular}{|l|r|r|}
\hline Tamaño & 1991 & 1994 \\
\hline Total & 13.7 & 10.25 \\
Grande & 69.8 & 73.0 \\
Mediano & 54.1 & 59.0 \\
Pequeño & 29.8 & 34.3 \\
Micro & 9.0 & 7.5 \\
\hline
\end{tabular}

Fuente: ENESTYC $(1992,1995)$, sTyPS.

\section{Cuadro 15}

Porcentaje del valor total de la maquinaria y equipo en establecimientos manufactureros en 1991 y 1994

\begin{tabular}{|l|cc|cc|}
\hline & \multicolumn{2}{|c|}{$\begin{array}{l}\text { Máquinas herramientas } \\
\text { de control numérico }\end{array}$} & \multicolumn{3}{|c|}{ Robots } \\
& 1991 & 1994 & 1991 & 1994 \\
\hline Total & 6.5 & 6.4 & 1.3 & 1.3 \\
Grande & 7.0 & 7.8 & 1.4 & 2.0 \\
Mediana & 7.1 & 8.1 & 2.0 & 1.1 \\
Pequeña & 5.5 & 5.0 & 0.3 & 0.6 \\
Micro & 1.2 & 1.6 & 0.0 & 0.2 \\
\hline
\end{tabular}

Fuente: ENESTYC $(1992,1995)$, sTyPS. 


\section{Cuadro 16}

Porcentaje de establecimientos manufactureros que realizaron cambios en la organización del trabajo

a partir de 1994

\begin{tabular}{|l|c|c|c|c|c|c|r|c|}
\hline Tamaño & I & II & III & IV & V & VI & VII & VIII \\
\hline Total & 14.7 & 3.5 & 2.9 & 18.0 & 3.9 & 14.9 & 6.4 & 1.3 \\
Grande & 64.1 & 7.0 & 5.8 & 12.1 & 10.7 & 14.4 & 16.0 & 3.4 \\
Mediano & 53.0 & 5.9 & 6.9 & 16.1 & 9.7 & 12.4 & 14.5 & 1.3 \\
Pequeño & 37.1 & 6.0 & 9.1 & 16.2 & 9.5 & 13.6 & 10.0 & 0.0 \\
Micro & 12.3 & 2.8 & 1.2 & 18.7 & 2.2 & 15.3 & 4.9 & 1.3 \\
\hline
\end{tabular}

Claves I Cualquier cambio en organización del trabajo en producción; II Justo a tiempo; III Rotación entre puestos; Iv Polivalencia; v Control estadístico del proceso; vI Equipos de trabajo; vII Círculos de calidad; vIII Unidades de negocios. Fuente: ENESTYC (1995), sTyPS.

rativa y, por tanto, puede suponerse que se trata de los contratos de las empresas más grandes y los que han sido más protectores de los trabajadores. Para el análisis de la flexibilidad numérica, funcional y salarial se han utilizado las mismas dimensiones e indicadores que para la encuesta MIM. Se tomó una muestra aleatoria por rama (tal como éstas se clasifican en la Junta Federal de Conciliación y Arbitraje) de alrededor del $10 \%$ del universo de contratos colectivos. De este análisis 9 puede concluir (De la Garza y Bouzas, 1998):

1. La flexibilidad funcional es alta en los contratos colectivos (lo cual no significa que esta flexibilidad se aplique en la práctica, pero sí que en la mayoría de los contratos lo contenido en sus cláusulas no es un obstáculo para la flexibilidad funcional). Se confirma también una antigua tesis que hemos manejado desde la década pasada, que el modelo de contratación colectiva de la Revolución Mexicana ha sido en México de la circulación, es decir con protecciones en empleo y salario (compraventa de la fuerza de trabajo), pero con poca participación formal de los sin- 


\section{Cuadro 17}

Porcentaje de trabajadores de planta, de tiempo parcial, por horas y subcontratados en establecimientos manufactureros en 1991 y 1994

\begin{tabular}{|l|rr|rr|rr|rr|}
\hline & \multicolumn{2}{|c|}{ De planta } & \multicolumn{2}{|c|}{ Tiempo parcial } & \multicolumn{2}{c|}{ Por horas } & \multicolumn{2}{c|}{ Subcontratados } \\
\hline Tamaño & 1991 & 1994 & 1991 & 1994 & 1991 & 1994 & 1991 & 1994 \\
\hline Total & 85.6 & 85.5 & 0.5 & 0.4 & 0.1 & 0.03 & 1.9 & 0.2 \\
Grande & 86.5 & 88.4 & 0.2 & 0.09 & 0.03 & 0.03 & 1.8 & 0.3 \\
Mediano & 86.2 & 86.4 & 0.3 & 0.09 & 0.06 & 0.01 & 1.6 & 0.0 \\
Pequeño & 89.1 & 91.8 & 0.8 & 0.6 & 0.4 & 0.02 & 1.7 & 0.3 \\
Micro & 77.1 & 78.4 & 1.3 & 0.7 & 0.1 & 0.05 & 2.7 & 0.0 \\
& & & & & & & &
\end{tabular}

Fuente: ENESTYC $(1992,1994)$, sтYPS.

\section{Cuadro 18}

Porcentaje de establecimientos manufactureros que ofrecen bonos por productividad a los obreros y porcentaje de dichos bonos en el salario obrero cuando existen en 1995

\begin{tabular}{|l|c|c|}
\hline Tamaño & $\begin{array}{c}\text { Tienen bonos } \\
\text { por productividad }\end{array}$ & $\begin{array}{c}\text { Porcentaje del bono } \\
\text { en el salario }\end{array}$ \\
\hline Total & 5.3 & 10.3 \\
Grande & 36.8 & 8.6 \\
Mediano & 29.1 & 8.9 \\
Pequeño & 17.6 & 8.4 \\
Micro & 3.9 & 11.1 \\
\hline
\end{tabular}

Fuente: ENESTYC (1995), sTyPS. 


\section{Cuadro 19}

Porcentaje de los costos laborales con respecto a los costos totales en establecimientos manufactureros en 1989 y 1994

\begin{tabular}{|ll|l|}
\hline Tamaño & \multicolumn{2}{c|}{ Porcentaje } \\
\hline & 1989 & 1994 \\
\hline Total & 24.7 & 16.9 \\
Grande & 25.2 & 15.4 \\
Mediano & 24.9 & 17.2 \\
Pequeño & 27.3 & 19.4 \\
Micro & 17.9 & 18.3 \\
\hline
\end{tabular}

Fuente: ENESTYC $(1992,1995)$, sTyPS.

dicatos en los procesos de trabajo. Es cierto que en cuanto a flexibilidad funcional (dentro del proceso de trabajo) lo que predomina es la indefinición en el contrato colectivo, pero en segundo término la unilateralidad explícita de las empreses en las decisiones La rigidez manifiesta codificada es poco frecuente y hay muy poca limitación formal a la movilidad interna, entre turnos 0 geográfica; las limitaciones son moderadas a la polivalencia de los trabajadores y, en general, la antigüedad no juega sola como criterio de ascenso de los trabajadores, tampoco depende sólo de la voluntad de los obreros el trabajar en horas extras o en días de descanso obligatorio.

2. En cambio, la regulación contractual de la flexibilidad numérica es muy superior a la funcional. Es alta en cuanto al empleo de eventuales; moderada aunque no mayoritaria en cuanto al uso por las empresas de subcontratistas; también en el uso de trabajadores de confianza y para el recorte de personal.

3. Por lo que se refiere a la flexibilidad salarial, sí hay una rigidez acentuada al predominar el salario mensual o quincenal fijo por categoría, y éste se encuentra muy regulado; hay poca importancia de los bonos de puntualidad y asistencia, productividad o ca lidad. 
La conclusión es muy clara: los contratos colectivos en México en general son flexibles en lo funcional, son mas rígidos en lo numérico y sobre todo en lo salarial. Es decir, los contratos parecieran más flexibles que las relaciones laborales en la práctica.

Entre 1990 y 1994, en la mayoría de las empresas los ítems considerados para medir la flexibilidad laboral no cambiaron. Sin embargo, en aquellos casos en que sí se modificaron, predominó la tendencia hacia una mayor flexibilidad. Es probable que el predominio de cláusulas no modificadas se deba a que la muestra no discriminó entre empresas grandes y de otros tamaños, y a que la flexibilización contractual esté concentrada en las grandes De cualquier manera de nuestra muestra se infiere que:

1. Se tendió más a excluir a los sindicatos de las decisiones de los cambios tecnológicos, métodos de trabajo, pero no en la negociación de la intensidad del trabajo.

2. La contratación de eventuales, trabajadores de confianza y la definición de cuáles trabajadores son de base tendieron a ser más flexibles, no asi el empleo de subcontratistas.

3. La movilidad entre puestos o categorías, turnos, geográfica, las horas extras, el criterio de ascenso y el trabajo en días de descanso obligatorio tendieron a flexibilizarse, a diferencia de la polivalencia.

4. El salario continuó siendo muy rígido.

Si analizamos los niveles de flexibilidad numérica, funcional y salarial por rama tenemos los siguientes resultados.

1. Por rama, los cambios en flexibilidad numérica son hacia mayor flexibilidad en todas excepto en la cinematografía, destacando los niveles más altos en la hulera, la metalurgia y siderurgia, automotriz y autopartes, aceites y grasas vegetales, maderera básica y tabacalera.

2. En cambio, la flexibilidad salarial tendió más hacia la rigidez en todas las ramas. 
En cuanto a los cambios en flexibilidad por entidad federativa

a) El cambio hacia la flexibilidad numérica fue positivo en todas las entidades federativas, en especial en Baja California, Distrito Federal, Durango, Guanajuato, Guerrero, Jalisco, Edo. de México y Morelos.

b) La flexibilidad funcional también tendió a aumentar en todas las entidades federativas, excepto en Nuevo León, aunque los índices son menores que los de flexibilidad numérica.

c) En cuanto a la flexibilidad salarial por entidad federativa, fue negativa en su incremento en todas.

\section{Flexibilidad, exportación y propiedad del capital}

En lo que respecta a la formalización del trabajo, el uso de manuales de puestos y su uso está más extendido en empresas extranjeras, así como la realización de estudios de tiempos y movimientos Las formas nuevas de organización del trabajo más comunes en las empresas exportadoras son los ćrculos de control de calidad y la redefinición del layout de las líneas de producción.

En cuanto a la flexibilidad laboral, la movilidad interna es muy parecida independientemente de que las empresas sean exportadoras o no, nacionales o extranjeras. El cálculo del nivel global de flexibilidad muestra lo siguiente:

Con respecto al nivel de involucramiento de los trabajadores en la producción, los valores altos son poco frecuentes tanto en empresas exportadoras como en las que no lo son, así como en las de capital nacional y extranjero. En todos los casos hay un claro predominio del involucramiento bajo.

En lo que se refiere a la concertación con los sindicatos y los trabajadores en los problemas de empleo, proceso de producción, sa lario, tecnología y organización del trabajo, los resultados de los dos cuadros siguientes muestran que el índice de bilateralidad total (formal e informal, con sindicato y/ o con los trabajadores) en exporta doras y no exportadoras es bajo y no hay diferencias importantes; 
entre extranjeras y nacionales también es bajo, pero es más bajo en las extranjeras.

En cuanto a las articulaciones de las empresas con su entorno, en términos de ubicación de sus proveedores y clientes y la formación de cadenas productivas a través de la subcontratación, los proveedores de las empresas extranjeras están básicamente en el extranjero, aunque la importancia de proveedores extranjeros entre las naciona les es mayoritario también; asimismo, el comercio intrafirma es ma yoritario entre las empresas extranjeras en México.

\section{Cuadro 20}

Existencia y uso de manuales de puestos (porcentaje de establecimientos)

\begin{tabular}{|l|c|c|}
\hline $\begin{array}{l}\text { Manuales de } \\
\text { puestos }\end{array}$ & Extranjeras & Nacionales \\
\hline Los usan & 81.8 & 50.5 \\
No los usan & 2.5 & 6.5 \\
No tienen & 15.7 & 43.1 \\
\hline
\end{tabular}

Fuente: MIM (1994).

\section{Cuadro 21}

Nivel global de flexibilidad (externa, interna y salarial) (porcentaje de establecimientos)

\begin{tabular}{|l|c|c|}
\hline $\begin{array}{l}\text { Índice de } \\
\text { Flexibilidad }\end{array}$ & Exportador & No exportador \\
\hline Bajo & 77.9 & 71.7 \\
Medio & 22.1 & 28.3 \\
\hline
\end{tabular}

Fuente: MIM (1994). 


\section{Cuadro 22}

Nivel de involucramiento

(porcentaje de establecimientos)

\begin{tabular}{|l|r|r|c|r|}
\hline \multirow{2}{*}{ Involucramiento } & \multicolumn{2}{|c|}{ Exportador } & \multicolumn{2}{c|}{ Propiedad del capital } \\
\hline & \multicolumn{1}{|c|}{ S' } & No & Extranjero & Nacional \\
\hline Bajo & 70.7 & 72.5 & 74.4 & 71.1 \\
Medio & 23.9 & 22.1 & 23.1 & 22.7 \\
Alto & 5.4 & 5.4 & 2.5 & 6.2 \\
\hline
\end{tabular}

Fuente: MIM (1994).

En lo concerniente al perfil de la fuerza de trabajo que utilizan las empresas, la escolaridad de los trabajadores promedio sigue siendo la primaria sin distinción de tipo de empresa; en cuanto a la antigüedad, los obreros profesionales (poseen un oficio) tiene en promedio entre 2 y 10 años sin distinción de tipo de empresa, los obreros especializados en determinadas máquinas también entre 2 y 10 años sin distinción por tipo de empresa; en cambio, los obreros generales tienen menos de 2 años en las empresas extranjeras y entre 2 y 5 en las nacionales. Los trabajadores eventuales son minoría en todos los tipos de empresas. Finalmente, el ingreso de los trabajadores es bajo en la mayoría de todos los tipos de empresas y los bonos por productividad,calidad, asistencia o puntualidad en la mayoría de todos los tipos constituyen entre 0 y $25 \%$ del total del ingreso del trabajador.

Con respecto a las diferencias entre empresas exportadoras y no exportadoras, así como de capital nacional y extranjero, podemos concluir que hacia 1994: 


\section{Cuadro 23}

Índice de bilateralidad total (porcentaje de establecimientos)

\begin{tabular}{|l|c|c|c|c|}
\hline \multirow{2}{*}{$\begin{array}{l}\text { Índice de } \\
\text { bilateralidad }\end{array}$} & \multicolumn{2}{|c|}{ Exportadores } & \multicolumn{2}{|c|}{ Capital } \\
\cline { 2 - 5 } & S' & No & Extranjero & Nacional \\
\hline Bajo & 52.1 & 53.0 & 64.8 & 48.9 \\
Medio & 35.7 & 36.9 & 30.7 & 38.0 \\
Alto & 12.1 & 10.1 & 4.5 & 13.1 \\
\hline
\end{tabular}

Fuente: MIM (1994).

\section{Cuadro 24}

Índice de bilateralidad formal entre sindicato y empresa

(porcentaje de establecimientos)

\begin{tabular}{|l|r|c|c|c|}
\hline \multirow{2}{*}{$\begin{array}{l}\text { Índice de } \\
\text { bilateralidad } \\
\text { formal }\end{array}$} & \multicolumn{2}{|c|}{ Exportadores } & \multicolumn{2}{c|}{ Capital } \\
\cline { 2 - 5 } & \multicolumn{1}{|c|}{ Sí } & No & Extranjero & Nacional \\
\hline Bajo & 77.4 & 78.2 & 83.3 & 75.0 \\
Medio & 17.1 & 18.7 & 13.5 & 19.7 \\
Alto & 5.5 & 3.1 & 3.1 & 5.3 \\
\hline
\end{tabular}

Fuente: MIM (1994).

\section{Cuadro 25}

Situación del principal proveedor de las empresas (porcentaje de establecimientos)

\begin{tabular}{|l|c|c|}
\hline Proveedor & \multicolumn{2}{|c|}{ Capital } \\
\hline & Extranjero & Nacional \\
\hline Nacional & 4.8 & 45.4 \\
Extranjero & 95.2 & 54.3 \\
\hline
\end{tabular}

Fuente: MIM (1994). 
1. En organización del trabajo pareciera que la división de éste en lo concerniente a las extranjeras tiende más a esquemas tayloristas fordistas más estrictos que en las nacionales, posiblemente porque en éstas haya mayor presencia de administración no científica. De la misma manera, las extranjerastienden más a formalizar el trabajo en sentido taylorista.

2. En niveles de flexibilidad del trabajo no parece haber diferencias entre tipos de empresas.

3. En bilateralidad, siendo baja en general, las extranjeras tienden menos a compartir las decisiones con sindicatos y trabajadores.

\section{Cuadro 26}

Utilización de subcontratistas en producción

(porcentaje de establecimientos)

\begin{tabular}{|l|c|c|c|c|}
\hline \multirow{2}{*}{$\begin{array}{l}\text { Usan } \\
\text { subcontratistas }\end{array}$} & \multicolumn{2}{|c|}{ Exportadoras } & \multicolumn{2}{c|}{ Capital } \\
\cline { 2 - 5 } & Sí & No & Extranjero & Nacional \\
\hline Sí & & & & \\
No & 15.2 & 17.4 & 17.5 & 15.5 \\
\hline
\end{tabular}

Fuente: MIM (1994).

\section{Cuadro 27}

Nivel de ingreso de los obreros

(porcentaje de establecimientos)

\begin{tabular}{|l|c|c|}
\hline Nivel de ingreso & Exportadora & No exportadora \\
\hline Bajo & 67.6 & 58.4 \\
Medio & 22.7 & 34.2 \\
Alto & 9.1 & 7.4 \\
\hline
\end{tabular}

Fuente: MIM (1994). 
4. En cuanto al salario, en todos los tipos el ingreso es bajo.

5. Con respecto a la fuerza de trabajo, la única diferencia es en cuanto a la mayor juventud y la menor antigüedad de ésta en las empresas extranjeras; en todas se trata de trabajadores de bajo nivel educativo.

Las empresas extranjeras en México al parecer llegan con esquemas de organización tayloristas-fordistas, mezclados con aplicaciones parciales de la calidad total y el justo a tiempo, pero en el fondo con una división del trabajo que sigue asignando a los obreros tareas poco calificadas en contraste con técnicos e ingenieros. En esta medida, el recambio importante de la fuerza de trabajo a nivel global no es por la creación de una capa importante de trabajadores recalificados, sino por la incorporación de fuerza de trabajo joven, femenina, de gran rotación externa y bajo salario y calificación.

El porcentaje de establecimientos que en 1994 realizaron actividades conjuntas de investigación, comercialización, capacitación, financiamiento o ventas es pequeño. Un ejemplo claro de este comportamiento que desarticula cadenas productivas y de clientes y proveedores es la maquila del norte, que, a pesar del discurso sobre clusters adoptado oficialmente, mantiene sus insumos nacionales en alrededor de $2 \%$ del total desde el inicio del actual modelo económico en 1982.

\section{Sindicatos, productividad y flexibilidad}

A pesar de las dificultades de los sindicatos en México a partir de 1982, la proporción de asalariados en la industria manufacturera y los trabajadores cubiertos por contratos escritos de trabajo sigue siendo muy alta, así como el porcentaje de trabajadores en este sector sindicalizados.

Analizaremos, utilizando datos de las encuestas ENESTYC y MIM, las relaciones entre sindicalización (sólo fue posible disponer del dato de si un establecimiento tenía sindicato y no la tasa de trabajadores sindicalizados en 1991) con indicadores de flexibilidad y de productividad. Las claves de las ramas manufactureras utilizadas son: 


\section{Cuadro 28}

\section{Asalaramiento y formalización de la relación laboral (1996)}

\section{Porcentajes}

\begin{tabular}{|l|c|c|c|}
\hline Rama & $\begin{array}{r}\text { Asalariados/ } \\
\text { Ocupados }\end{array}$ & $\begin{array}{c}\text { Asalariados con } \\
\text { contrato de base } \\
\text { escrito }\end{array}$ & $\begin{array}{c}\text { Asalariados con } \\
\text { contrato de base o } \\
\text { eventual escrito }\end{array}$ \\
\hline Agropecuario & $28.2 \%$ & $7.6 \%$ & $9.9 \%$ \\
Minas & 90.3 & 73.5 & 79.8 \\
Petróleo & 99.9 & 75.5 & 98.9 \\
Transformación & 74.9 & 55.3 & 67.2 \\
Electricidad & 99.6 & 85.8 & 96.0 \\
Construcción & 70.1 & 13.8 & 23.0 \\
Comercio & 44.7 & 45.5 & 54.2 \\
Hoteles, restaurantes & 51.1 & 37.7 & 46.2 \\
Transportes y conexos & 74.5 & 37.4 & 44.0 \\
Comunicaciones & 96.6 & 87.6 & 93.7 \\
Alquiler de inmuebles, & & & \\
Servicios financieros & & 62.3 & 74.7 \\
y profesionales & 75.6 & 47.3 & 53.7 \\
Otros servicios & 72.8 & 80.8 & 93.7 \\
Administración & & 33.3 & 50.3 \\
pública y defensa & 99.6 & 91.0 & 3 \\
No especificado & & & \\
\hline
\end{tabular}

Fuente: INEGI (1996), Encuesta Nacional de Empleo. 


\section{Cuadro 29}

Porcentaje de establecimientos manufactureros que cuentan con sindicato y trabajadores sindicalizados en 1991 y 1995

\begin{tabular}{|c|c|c|c|}
\hline \multirow[t]{2}{*}{ Tamaño } & \multicolumn{2}{|c|}{$\begin{array}{l}\text { Porcentaje con } \\
\text { sindicato }\end{array}$} & \multirow{2}{*}{$\begin{array}{c}\text { Porcentaje de } \\
\text { trabajadores } \\
\text { sindicalizados en } 1995\end{array}$} \\
\hline & 1991 & 1995 & \\
\hline Total & 15.2 & 14.1 & 42.2 \\
\hline Grande & 87.1 & 89.5 & 63.9 \\
\hline Mediano & 84.0 & 84.5 & 58.3 \\
\hline Pequeño & 66.0 & 60.1 & 46.5 \\
\hline Micro & 6.9 & 9.5 & 14.2 \\
\hline
\end{tabular}

Fuente: ENESTIC (1992, 1995), sтYPS.

\section{Cuadro 30}

Porcentaje de establecimientos manufactureros que cuentan con sindicato en 1991 y 1995, porcentaje de trabajadores sindicalizados en 1995 por rama

\begin{tabular}{|l|rr|c|}
\hline Rama & \multicolumn{2}{|c|}{ Establecimiento } & Trabajadores \\
& \multicolumn{2}{|c|}{ con sindicato } & Sindicalizados \\
& 1991 & 1995 & (\%) 1995 \\
\hline Nacional & 15.2 & 14.1 & 42.2 \\
Alimentos, bebidas y tabaco & 9.0 & 9.0 & 37.8 \\
Textiles, prendas de vestir y calzado & 21.2 & 21.0 & 42.6 \\
Industria de la madera & & & \\
y productos de madera & 8.1 & 6.2 & 25.4 \\
Papel, productos de papel,imprenta & 11.3 & 15.0 & 37.2 \\
y editoriales & 59.7 & 53.2 & 51.1 \\
Química,derivados del carbón, hule y plástico & 13.5 & 11.6 & 44.1 \\
Minerales no metálicos & 54.1 & 77.6 & 64.4 \\
Industrial metálicas básicas & 18.8 & 19.7 & 47.6 \\
Productos metálicos, maquinaria y equipo & 35.0 & 15.6 & 48.1 \\
Otras industrias manufactureras & & \\
\hline
\end{tabular}

Fuente: elaboración propia a partir de la ENESTIC, STYPS, 1994. 


\section{Cuadro 31}

Sindicalización, productividad, innovación y flexibilidad en la industria manufacturera por rama de actividad, datos de 1991

\begin{tabular}{|l|r|r|r|r|r|r|r|}
\hline Rama & \multicolumn{1}{|c|}{ I } & II & III & IV & V & VI & VII \\
\hline Total & 15.2 & 79.4 & 2.4 & 13.9 & 21.2 & 35.8 & 41.0 \\
3100 & 9.0 & 82.2 & 0.6 & 9.7 & 13.5 & 2.4 & 40.5 \\
3200 & 21.2 & 38.5 & 8.3 & 15.8 & 18.7 & 3.1 & 39.0 \\
3300 & 8.1 & 62.4 & 2.2 & 10.1 & 28.2 & 2.7 & 32.4 \\
3400 & 11.3 & 79.6 & 1.5 & 21.4 & 17.2 & 3.5 & 55.1 \\
3500 & 59.7 & 104.6 & 5.3 & 48.6 & 41.7 & 15.2 & 69.8 \\
3600 & 13.5 & 68.4 & 1.5 & 9.9 & 26.3 & 3.2 & 35.7 \\
3700 & 54.1 & 142.1 & 1.0 & 48.8 & 33.6 & 13.2 & 56.9 \\
3800 & 18.8 & 89.1 & 1.8 & 15.2 & 27.0 & 4.4 & 40.1 \\
3900 & 35.0 & 38.8 & 17.7 & 22.5 & 26.0 & 2.4 & 57.8 \\
r & - & 0.545 & 0.272 & 0.949 & 0.791 & 0.897 & 0.818 \\
\hline
\end{tabular}

Fuente:elaboración propia a partir de la ENESTIC.

$r=$ coeficiente de correlación entre I y las demás variables de las columnas.

3100 productos alimenticios, bebidas y tabacos

3200 textiles, prendas de vestir e industria del calzado

3300 industrias de la madera y productos de madera

3400 papel, productos de papel, imprentas y editoriales

3500 substancias químicas, productos derivados del carbón, hule y plástico

3600 productos minerales no metálicos

3700 industrias metálicas básicas

3800 productos metálicos, maquinaria y equipo

3900 otras industrias manufactureras

La productividad se calculó como valor agregado entre personal total ocupado 
Las claves de las columnas son:

$\mathrm{I}$ = Porcentaje de establecimientos que tiene sindicato

II = Productividad

III= Porcentaje de establecimientos que tienen tecnología novedosa

IV = Porcentaje de establecimientos que realizaron cambios

en la organización de la producción a partir de 1987

$v=$ Porcentaje de establecimientos que emplearon

trabajadores eventuales

VI= Porcentaje de establecimientos que utilizaron subcontratistas

$\mathrm{VII}=$ Porcentaje de establecimientos que practican la participación

de los trabajadores en el mejoramiento de la productividad

VIII= Tasa de rotación entre puestos

Del cuadro anterior se puede deducir que la presencia de sindicatos en establecimientos manufactureros se correlaciona positiva mente con: productividad, tecnología novedosa, cambio en organización del trabajo, empleo de trabajadores eventuales, participación de subcontratistas y participación de los trabajadores en el mejora miento de la productividad

Adicionalmente, por rama manufacturera, el coeficiente de correlación entre innovación en el producto y sindicalización fue de 0.594; para el uso de subcontratistas y sindicalización, de 0.67; pa ra el porcentaje de trabajadores que recibieron capacitación y sindicalización, de 0.69 .

Es cierto que estas correlaciones positivas altas entre sindicaliza ción y modernización de la empresa no necesariamente significan que el sindicato sea un agente activo y participativo en esta modernización. Nuestras mediciones de bilateralidad apuntan en sentido contrario, pero al menos pueden significar que no son un obstáculo para la innovación en las empresas y la flexibilidad del trabajo.

En el cuadro 32, se observa que las empresas grandes son las más innovadoras y a la vez las de mayor sindicalización. También los resultados de la encuesta mim, analizados en los cuadros 33 y 34, muestran correlaciones positivas entre sindicalización y productividad.

También encontramos una correlación positiva pero menosfuerte que para las variables de innovación y flexibilidad laboral entre sindicalización y salario promedio por obrero. 


\section{Cuadro 32}

Sindicalización, productividad, innovación y flexibilidad en la industria manufacturera según tamaño de establecimiento, datos de 1991

\begin{tabular}{|l|r|r|r|r|c|c|c|c|}
\hline Tamaño & I & II & III & IV & V & VI & VII & VIII \\
\hline Grande & 87.1 & 96.2 & 11.5 & 66.3 & 68.3 & 20.0 & 17.9 & 74.6 \\
Mediano & 84.0 & 77.3 & 9.2 & 62.8 & 60.4 & 13.8 & 17.1 & 68.0 \\
Pequeño & 66.0 & 65.4 & 5.5 & 47.8 & 41.3 & 14.3 & 18.1 & 67.5 \\
Micro & 6.9 & 41.5 & 1.8 & 8.2 & 17.3 & 1.91 & 2.4 & 36.9 \\
r & - & 0.93 & 0.93 & 0.99 & 0.96 & 0.95 & 0.90 & 0.98 \\
\hline
\end{tabular}

Fuente: ibid.

\section{Cuadro 33}

Nivel de la productividad y sindicalización en la industria manufacturera, 1994 (porcentaje de establecimientos por nivel de productividad)

\begin{tabular}{|l|c|c|}
\hline Nivel de productividad & Sí tienen sindicato & No tienen sindicato \\
\hline Baja & 53.6 & 46.4 \\
Mediana & 100.0 & 0.0 \\
Alta & 73.3 & 26.3 \\
\hline
\end{tabular}

Fuente: UAMI, MIM, 1994.

De cualquier manera, la trayectoria de los salarios reales en los noventa sigue en la manufactura una curva con máximo en 1994 y caída sostenida desde entonces.

De acuerdo con el cuadro 36, se confirma la correlación alta en 1991 y 1994 entre tener sindicato y remuneración promedio por trabajador; correlación que es muy alta entre tener sindicato y cambio en la organización del trabajo. 


\section{Cuadro 34}

Sindicalización y nivel de la productividad en la industria manufacturera, datos de 1994 (porcentaje de establecimientos)

\begin{tabular}{|c|c|c|c|}
\hline Tiene sindicato & Productividad baja & Productividad media & Productividad alta \\
\hline S'́ & 88.3 & 0.51 & 11.2 \\
No & 94.9 & 0.0 & 5.1 \\
\hline
\end{tabular}

Fuente: UAMI, MIM, 1994.

\section{Cuadro 35}

Sindicalización y salario promedio mensual por obrero por rama manufacturera, datos de 1992

\begin{tabular}{|l|c|c|}
\hline Rama & Tasa de sindicatos & $\begin{array}{c}\text { Salario promedio } \\
\text { (nuevos pesos de 1992) }\end{array}$ \\
Total & 15.2 & 1459.8 \\
3100 & 9.0 & 1213.9 \\
3200 & 21.2 & 1122.9 \\
3300 & 8.1 & 1540.6 \\
3400 & 11.3 & 1518.3 \\
3500 & 59.7 & 1900.6 \\
3600 & 13.5 & 1465.9 \\
3700 & 54.1 & 1650.0 \\
3800 & 18.8 & 1627.8 \\
3900 & 35.0 & 1067.0 \\
\hline
\end{tabular}

Fuente: ENESTIC, STYPS, 1992.

Coeficiente de correlación:0.442 


\section{Cuadro 36}

Coeficientes de correlación entre sindicalización

(porcentaje de establecimientos con sindicato)

y otras variables en el sector manufacturero en 1991 y 1994

\begin{tabular}{|l|r|r|}
\hline Variable & \multicolumn{1}{|c|}{1991} & 1994 \\
\hline $\begin{array}{l}\text { Remuneraciones promedio por trabajador } \\
\text { Porcentaje de establecimientos }\end{array}$ & 0.5878 & 0.7003 \\
$\begin{array}{l}\text { que cambiaron la organización del trabajo } \\
\text { Porcentaje con bonos por productividad }\end{array}$ & 0.854 & 0.8029 \\
$\begin{array}{l}\text { Porcentaje de trabajadores de planta } \\
\text { Porcentaje de trabajadores }\end{array}$ & 0.1704 & 0.4736 \\
con nivel secundaria o más & 0.452 & n.d. \\
\hline
\end{tabular}

Fuente: elaboración propia a partir de las ENESTIC de 1991 y 1994.

\section{Conclusiones}

La modernización de las empreses exportadoras no es tan especta cular como pudiera pensarse, posiblemente porque la ventaja comparativa del bajo salario sigue siendo una realidad en muchas de éstas. Empresas exportadoras con bajos salarios, con fuerza de trabajo poco calificada y de nivel educativo bajo, con tecnologías intermedias, con aplicaciones parciales de la calidad total y el justo a tiempo, especialmente con poco involucramiento de los trabajadores, con esquemas de bonos por productividad poco atractivos para los obreros y baja bilateralidad con los sindicatos, parecieran más basadas en $\mathrm{el}$ bajo salario y la racionalización con gran intensidad del trabajo que en la constitución de cualquier forma de postfordismo o de lean production. La reestructuración productiva en México es real pero sigue caminos propios de acuerdo con las estrategias empresariales, el contexto institucional particular, las políticas estatales y las características previas de las relaciones laborales, de los sindicatos y las culturas de estos actores Taylorismo-fordismo con aspectos parciales de 
la calidad total y el justo a tiempo, todo esto con una división del trabajo que sigue segmentando las tareas de operación en el piso de las de concepción; por ello la reestructuración en general no se acompaña con mayor calificación ni capacitación obreras y el recambio en el perfil de la fuerza de trabajo es más entre la antigua clase obrera, de educación baja, calificada en la práctica en el uso de una máquina, masculina, de antigüedad y edad medianas y bajo sa lario, con una nueva fuerza de trabajo más femenina, joven, de alta rotación externa, baja calificación y también bajo salario.

Frente a la constatación de una extensión limitada de la flexibilidad laboral en México o bien muy focalizada en grandes empresas, caben varias hipótesis.

1. No se extiende la flexibilidad porque el paraguas de la Ley Federal del Trabajo lo impide. Esta hipótesis puede tener parte de verdad en cuanto a las indemnizaciones que la ley establece por despido injustificado y la existencia del contrato por tiempo indeterminado. Sin embargo, la misma ley contempla diversas formas de contratación: por obra, por tiempo determinado, además del indeterminado. En cuanto a las causas de suspensión de la relación laboral, la ley no considera las variaciones en la producción. Sin embargo, en el artículo 439 sí se toma en cuenta la posibilidad de reducción de personal al implantar nueva maquinaria o métodos de trabajo. Con respecto al ascenso de los trabajadores en el escalafón, el artículo 154 da preferencia a la antigüedad, pero sólo en igualdad de condiciones, mientras que el artículo 159 contempla que los ascensos se den a la categoría inmediata anterior y que el ascenso corresponderá al más apto y antiguo. En cuanto a la flexibilidad interna, efectivamente la ley establece en su artículo 24 que las condiciones de trabajo deberán contener el servicio o los servicios que el trabajador debe prestar y que éstos se definirán con la mayor precisión. Por lo que respecta a la flexibilidad salarial, el concepto de salario mínimo contenido en la ley no tiene que ver con el desempeño del trabajador sino con los costos de reproducción de la fuerza de trabajo y su familia; sin embargo, la ley abre la posibilidad del pago por obra, comisión, precio alzado o cualquier otra forma.Asimismo, el ar- 
tículo 84 dice que formarán parte del salario la cuota diaria,gra tificaciones, percepciones, habitación, primas, comisiones, prestaciones y horas extras. Finalmente, la ley no contempla explícitamente la participación de los sindicatos en las decisiones en materia de producción, de cambios tecnológicos o de reorganización del trabajo.

En síntesis, la Ley Federal del Trabajo contiene elementos de rigidez y a la vez de flexibilidad. El problema central, por tanto, no es la ley, sino cómo se acuñaron las costumbres laborales en México, cómo éstas repercutieron en la forma de los contratos colectivos, de tal manera que ciertas opciones de contratación que la ley permite no fueron practicadas. La prueba está en que en México algunos de los contratos colectivos más importantes han sido flexibilizados a pesar de que la ley no ha cambiado.

2. La otra explicación de por qué la mayoría de los contratos colectivos en México no han cambiado en los últimos años sería porque ya eran flexibles sobre todo en lo funcional, dado el desinterés sindical por los problemas de la producción. Nuestra investigación empírica es consistente con esta explicación, los contratos flexibilizados son los de las grandes empresas que sí eran protectores del trabajo más allá de las condiciones del mercado. Habría que añadir, que aunque ese núcleo de contratos del patrón contractual de la Revolución Mexicana ha sido flexibiliza do, en general no se ha llegado a los extremos de los contratos de la maquila del norte. Esta explicación es consecuente con el hallazgo empírico de que la flexibilidad en la gran empresa en México no adquiere caracteres extremos sino de nivel medio; aún más, que flexibilidades extremas codificadas en contratos como la Ford de Hermosillo en la práctica se han tenido que moderar por su efecto negativo en el desempeño de los trabajadores. La razón puede ser la contradicción entre una flexibilidad extremista - dejar al libre mercado hacer su labor asignadorafrente a una flexibilidad moderada toyotista, para la cual la extrema inseguridad en el trabajo o las multitareas indiscriminadas pueden provocar un clima laboral contrario a la identidad del trabajador con la empresa (Pollert, 1991; Tolliday, 1992; Wood, 1991). En otras palabras, es probable que haya una distancia en- 
tre el discurso empresarial de cúpula que habla de la flexibilidad extremista como condición de competitividad y lo que los empresarios establecen en sus empresas, al menos en ese núcleo de procesos productivos complejos que es el que se ha flexibilizado en este periodo.

3. Si las formas y contenidos de la flexibilidad en México son diversos, se debe sobre todo a las diferentes estrategias em presaria les de modernización (dejamos fuera las formas de flexibilidad previas a la reestructuración productiva actual). Está visto que estas estrategias pueden ser varias, pero pudieran resumirse en dos principales:

a) Por un lado, la que trata de ganar competitividad y productividad a través de nuevas formas de organización del trabajo que implican algún tipo de flexibilidad y cambio cultural. Sin embargo, esta forma se enfrenta en la actualidad a la constatación de que se establece la flexibilidad y se pide involucramiento e identidad con los fines de la empresa con escasa capacitación, baja delegación de poder de decisión a los obreros y bajos salarios.

b) La segunda forma $s$ asimila a la idea de flexibilidad como desregulación unilateral en favor de la empresa también con bajos salarios. Es decir, las formas dominantes de la flexibilidad en México se enfrentan a contradicciones importantes, tensiones potenciales y distancia entre discursos, sobre todo entre el toyotista y la realidad.

4. Las formas predominantes y contenidos de la flexibilidad no son ajenas a la manera en que los actores y sus organizaciones se desempeñan en los sistemas de relaciones industriales y en México también en el sistema político. La presencia del corporativismo sindical, la permanente injerencia gubernamental en las relaciones laborales, así como las culturas y estrategias autoritarias de los empresarios han contribuido a que formas cercanas, salvo excepciones, a la desregulación de nivel intermedio del trabajo en favor de las gerencias sean las que predominan en México, con profundas diferencias según el tamaño de los establecimientos. 
En ś́ntesis, un cambio democratizador en las relaciones labora les en México por ahora no parece emprenderse a partir de las empresas, ni del Estado y menos de los sindicatos. Es probable que pa ra ello se tenga primero que esperar a que se transforme más el sistema político y de ahí impactar a las relaciones laborales en el nivel de la empresa.

Recibido en abril de 1999

Revisado en agosto de 1999

\section{Bibliografía}

Arteaga, A. (1988), "Reconversión industrial y flexibilidad del tra bajo en la industria automotriz en México, 1981-1986", en E. Gutiérrez Garza (coord.), Austeridad y reconversión, tetimonio de la crisis 3, México, Siglo XXI.

y V. J. Carrillo (1990), "Automóvil: Hacia la flexibilidad productiva", El Cotidiano, no. 21.

(coord.) (1992), Proceso de trabajo y relaciones laborales en la in dustria automotriz en M éxico, México, UAM-Fundación Friedrich Ebert.

Bensusan, G. (1995), "La propuesta panista de un nuevo modelo de regulación laboral", La Jornada, 28 de octubre

y C. García (coords.) (1990a), Relaciones laborales en las empre sas paraestatales, México, Fundación Friedrich Ebert.

(1990b), Cambios en las relaciones laborales:Cuatro experiencias en transición, México, Fundación Friedrich Ebert

Bouzas, J. A. (1996), Bancomer:Reprivatización de la banca y flexibilización de las relaciones laborales, México, IIEC, UNAM.

Buroway, M. (1985), The Politics of Production, Londres, Verso. 
Carrillo, J. (coord.) (1993), Condiciones de empleo y capacitación en las ma quiladoras de exportación en M éxico, Tijuana, Secretaria del Trabajo y Previsión Social y El Colegio de la Frontera Norte.

(1995), "Adaptación de la producción flexible y cualifica ción en el sector automotriz", Sociología del Trabajo, no. 21.

y A. Hualde (1990), "Maquiladoras: La reestructuración industrial y el impacto sindical", en G. Bensusan y León (coord.), Negociación y conflicto laboral en México, México, Fundación Friedrich Ebert y FLACSO, pp.175-200

y M.A. Ramírez (1990), "Maquiladoras en la frontera norte: Opinión sobre los sindicatos", en Frontera Norte, vol.2, no. 4, julio-diciembre, pp.121-152.

Contreras, 0. y M. A. Ramírez Sánchez (1992), "Mercado de traba jo y relaciones laborales en Cananea. La disputa en torno a la flexibilidad", Trabajo, no. 8.

Covarrubias, A. (1992), La flexibilidad laboral en Sonora, Hermosillo, El Colegio de Sonora y Fundación Friedrich Ebert

y B. Lara (coords.) (1993), Relaciones industriales y productividad en el norte de México: Tendencias y problemas, México, Fundación Friedrich Ebert

De la Garza, E.(1990), “Reconversión industrial y cambiosen el patrón de relaciones laborales en México", en A. Anguiano (comp.), La modernización de México, México, UAM-X.

(1992), "El Tratado de Libre Comercio y sus consecuencias en la contratación colectiva", El Cotidiano, no. 45.

(1993a), "Reestructuración productiva y respuesta sindical en América Latina", Sociología del Trabajo, no. 19. 
(1993b), Restructuración productiva y respuesta sindical en México, México, México, IIEC-unam.

(1993c), "Reestructuración del corporativismo en México: Siete tesis", El Cotidiano, no. 50.

y J. Melgoza (1994), "Estrategias sindicales y productividad en México", ponencia para el seminario Equalities and $\mathrm{NeN}$ Forms of Popular Representation in Latin America, NuevaYork,U niversidad de Columbia.

(1995), “Cogestión, calidad total y sistema de relaciones industriales", en Competitividad vs democracia industrial, México, Fundación Friedrich Ebert.

(1997a), "La flexibilidad del trabajo en América Latina”, Revista Latinoamericana de Estudios de Trabajo, no. 5.

(1997b), La formación soci oeconómica neoliberal, México, UAM

y A. Bouzas (1998), La flexibilidad del trabajo en M éxico, MéxiCO, IIEC-UNAM.

(1998), Modelos de industrialización en M éxico, México, styPS.

De Buen, N. (1989), La flexibilidad en el derecho de trabajo, México, Fundación Friedrich Ebert.

De la $O$ Martínez, M. E. y C. Quintero (1992), "Sindicalismo y contratación colectiva en las maquiladoras fronterizas. Los casos de Tijuana, Ciudad Juárez y Matamoros", Frontera N orte, no. 8, El Colegio de la Frontera Norte, julio-diciembre.

Dombois, R. y L. Pries (eds.) (1993), Trabajo industrial en la transición:ex periencias de América Latina y Europa, Caracas, Fundación Friedrich Ebert de México, El Colegio de Puebla y Nueva Sociedad. 
Gutiérrez Garza, E. (1988), Testimonios de la crisis, México, Siglo xxı.

Henk, T. (1995), Globalization, Londres, Zed Books.

Hernández Laos, E. y J. Aboites (1990), Identificación de los factores que obstaculizan la movilidad de la mano de obra en el sector industrial mexicano, México, sтyPs.

Le Goff, J. (1992), “LesTechnologies de la Qualité au Chile”, Sociolo gie du Travail, no. 2.

Leyva, M.A., (1995), Poder y domi nación en ferrocarriles nacionales de México. 1970-1988, México, Universidad Autónoma Metropolitana y Fundación Friedrich Ebert.

Montiel,Y. (1991), Organización de trabajo y relaciones laborales en vw, México, Cuadernos de la Casa Chata.

Organización Internacional del Trabajo (1997), El trabajo en el mundo, Ginebra, olT.

Piore, M. y Ch. Sabel ( 1990) , La segunda ruptura industrial, Madrid,Alianza.

Pollert,A. (1991), Farewdl to Flexibility, Londres, Berg.

Pozas, M. de los A. (1992), Reestructuración industrial en M onterrey, México, Fundación Friedrich Ebert, Documentos deTrabajo no. 40.

Quintero, C. (1993), "Tendencias sindicales en la frontera norte de México", El Cotidiano, no. 56.

Rodríguez,E.(1992), “Crisis, reestructuración y flexibilidad" en Es tudios Sociales, Revista de Investigación del Noroeste, vol, III, no. 6, julio-diciembre. 
Román, S.(1992), Relaciones laborales en la industria del hule, México, Fundación Friedrich Ebert, Documentos de Trabajo, no. 38.

Rueda, I. et.al. (1993), Tras las huellas de la privatización. El caso deAltos Hor nos de México, México, Siglo xxı.

Schumann, M. (1998), “New Concepts of Production and Productivity", Economic and Industrial Democracy, no. 19, 1.

Tolliday, S. (1992), Bewwen Fordism and Flexibility, Londres, Berg

Wilde, G. R. et. al. (1995), Nueva cultura productiva. Estrategias empresariales y sindicales, México, Fundación Friedrich Ebert.

Wood, S. (1991), "Japanization and or Toyotaism", Work Employment and Society, no. 5, 4.

(1993), "The Japanization of Fordism", Economic and Indus trial Relations, no. 14. 
